\title{
Thermo-mechanical ratcheting in jointed rock masses
}

\author{
C. PASTEN*, M. GARCÍA $\dagger$ and J. CARLOS SANTAMARINA
}

\begin{abstract}
Thermo-mechanical coupling takes place in jointed rock masses subjected to large thermal oscillations. Examples range from exposed surfaces under daily and seasonal thermal fluctuations to subsurface rock masses affected by engineered systems such as geothermal operations. Experimental, numerical and analytical results show that thermo-mechanical coupling can lead to wedging and ratcheting mechanisms that result in deformation accumulation when the rock mass is subjected to a biased static-force condition. Analytical and numerical models help in identifying the parameter domain where thermo-mechanical ratcheting can take place.
\end{abstract}

KEYWORDS: finite-element modelling; model tests; repeated loading; temperature effects

ICE Publishing: all rights reserved

\section{INTRODUCTION}

Energy conservation and Le Chatelier's principle state that a system in equilibrium could experience a mechanical reaction to oppose an imposed thermal change. This observation anticipates - but does not explain - thermally driven displacements that have been recognised in natural rock slopes (Hatzor, 2003; Watson et al., 2004; Gunzburger et al., 2005; Gischig et al., 2011; Bakun-Mazor et al., 2013; Pasten, 2013; Greif et al., 2014) and engineered systems such as pavement structures, exposed geomembranes and thermo-active piles (Croll, 2009; Pasten \& Santamarina, 2014a, 2014b).

The accumulation of displacements in rock masses due to thermo-mechanical effects requires a force-biased system such as a down-sliding driving wedge or choke-stones behind a resisting block, a single block on an inclined plane, or a combination thereof. The general case is sketched in Fig. 1: a resisting block of height $H(\mathrm{~m})$ and width $L_{\mathrm{B}}(\mathrm{m})$ and a driving wedge of width $L_{\mathrm{W}}(\mathrm{m})$ sit on an inclined plane of angle $\eta$ (degrees). A thought experiment suggests the following sequence of events leading to displacement accumulation or ratcheting: plastic displacements take place along the block-base joint during heating; these displacements are only partially reversed during cooling; the driving wedge falls further down to a lower position and is ready to exert a renewed wedging action against the block during the following heating cycle.

The following section presents experimental evidence of thermo-mechanical wedging and ratcheting. A numerical model is validated against experimental results, and is later used to explore other boundary conditions. Finally, a simplified analytical model is developed to extract the parameter domain for thermo-mechanical ratcheting; in particular, we seek to obtain a closed-form solution to predict the minimum temperature change required for thermo-mechanical ratcheting as a function of the system geometry.

Manuscript received 26 December 2014; first decision 2 March 2015; accepted 26 March 2015.

Published online at www.geotechniqueletters.com on 15 July 2015.

*Department of Civil Engineering, University of Chile, Santiago, Chile

†Department of Geology, University of Chile, Santiago, Chile ¥Physical Science and Engineering Division, King Abdullah University of Science and Technology, Thuwal, Saudi Arabia

\section{EXPERIMENTAL DEMONSTRATION}

The experimental setup consists of an acrylic block-wedge system that reacts against an aluminium base and back wall (Fig. 2; further details are given elsewhere (Pasten, 2013)). The thermal expansion of the acrylic block-wedge elements $\left(\alpha_{\text {acrylic }}=85 \times 10^{-6} /{ }^{\circ} \mathrm{C}\right)$ exceeds the expansion of the aluminium base-wall $\left(\alpha_{\text {aluminium }}=20 \times 10^{-6} /{ }^{\circ} \mathrm{C}\right)$. The block-wedge system and the frame are housed within a temperaturecontrolled chamber. Air and block temperatures are monitored with thermocouples, and a linear variable differential transformer (LVDT) mounted outside the chamber tracks the wedge vertical displacement. Temperatures and displacement are recorded every $5 \mathrm{~s}$ using a data logging system.

Experimental results gathered for a horizontal base $\eta=0^{\circ}$ and a block-wedge interface at $\beta=6^{\circ}$ are shown in Fig. 3(a) (the experimental study involved 24 experiments under different thermal regimes and inclinations $\eta$ ). The time history exhibits three stages - initial heating $(\approx 2 \mathrm{~h})$, thermal cycles $\left(20\right.$ cycles, thermal amplitude $\Delta T=1 \cdot 4^{\circ} \mathrm{C}$, total

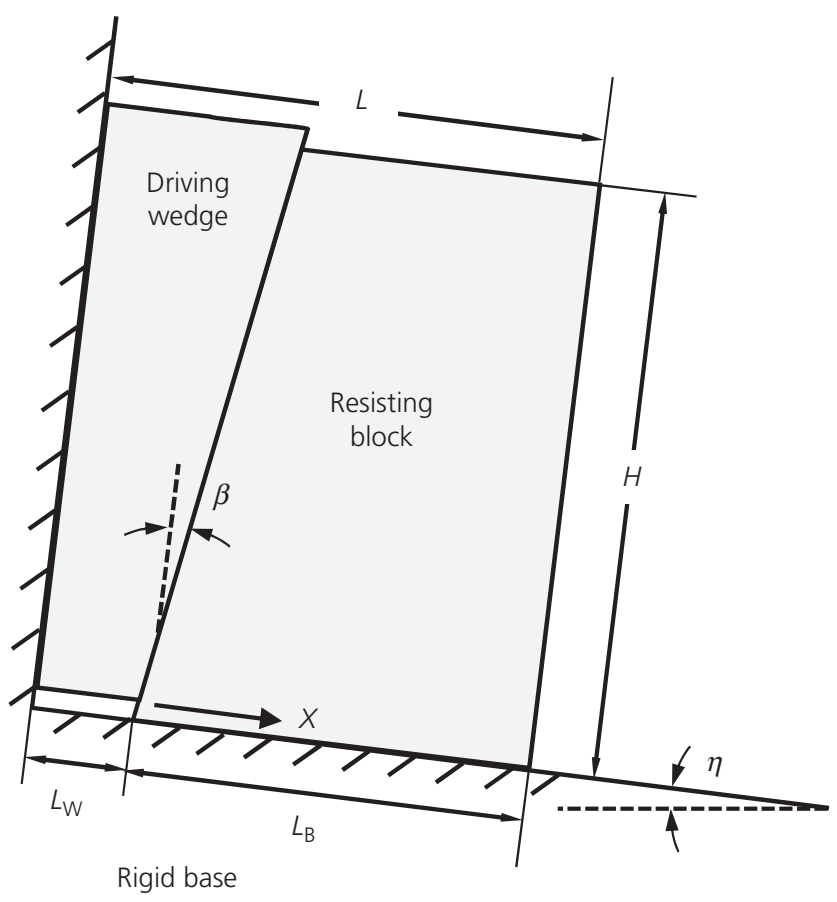

Fig. 1. Model configuration for thermo-mechanical ratcheting 


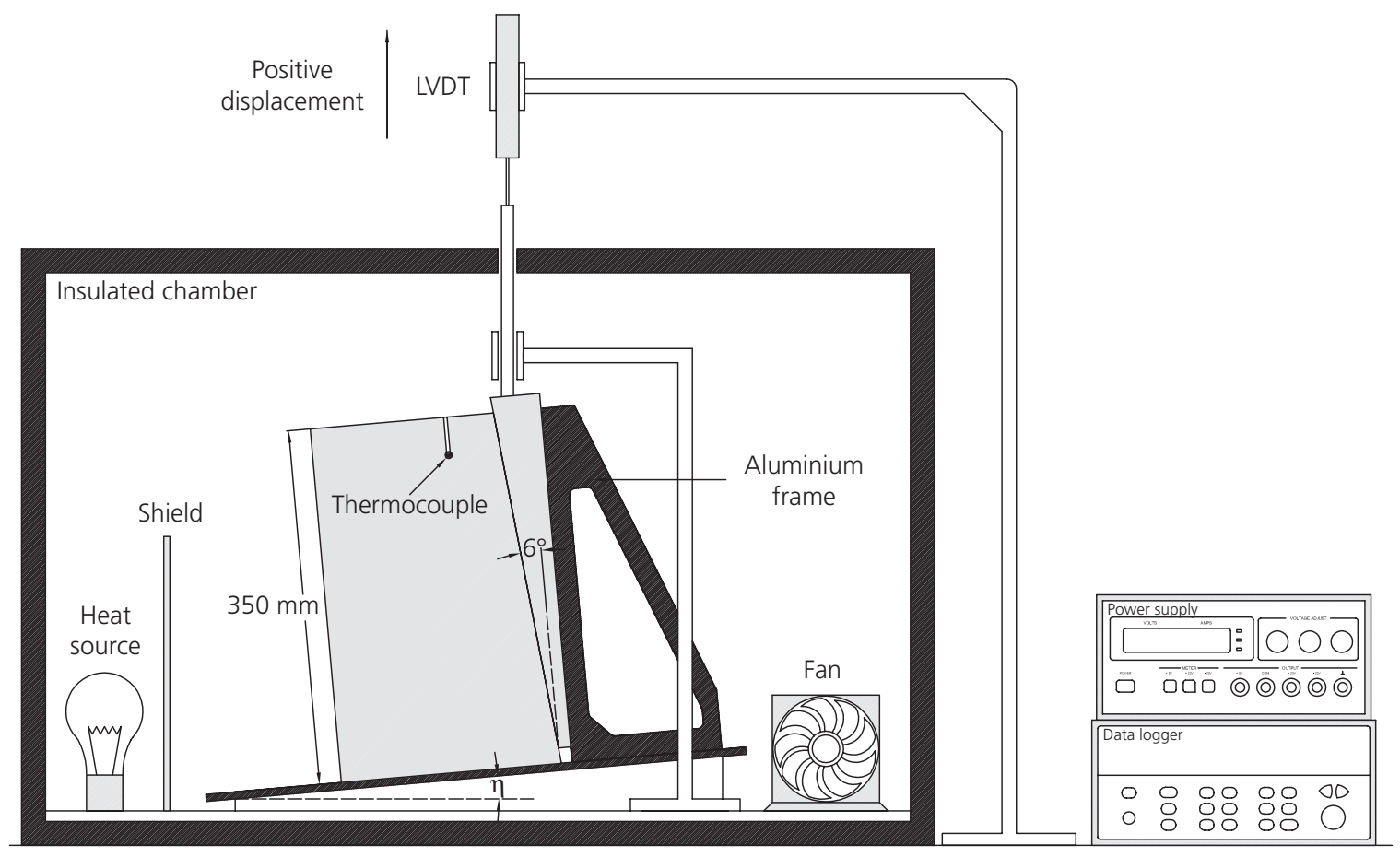

Fig. 2. Experimental setup

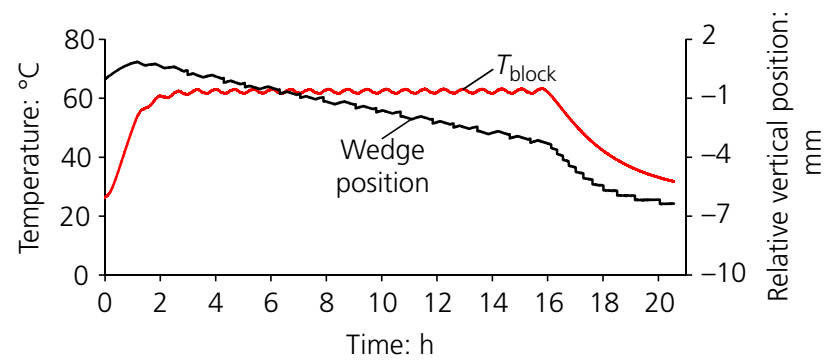

(a)

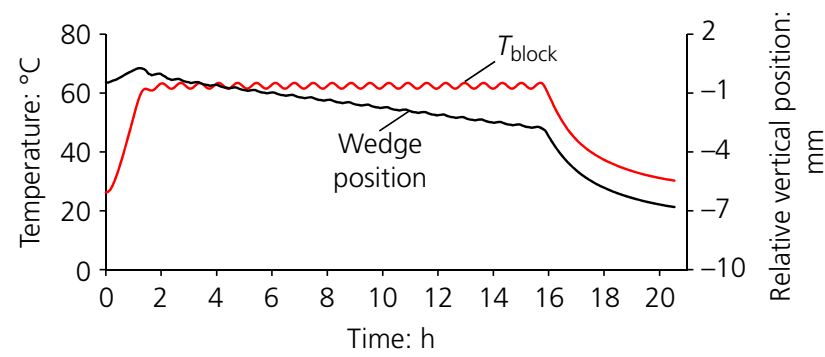

(b)

Fig. 3. Thermally induced wedging mechanism and ratcheting displacement for horizontal base $\eta=0^{\circ}$ : (a) experimental results and (b) numerical results of 3D model; $L_{\mathrm{B}}=213 \mathrm{~mm}, L_{\mathrm{W}}=12$ $\mathrm{mm}, H=350 \mathrm{~mm}$ and $\beta=6^{\circ}$

duration $\approx 14 \mathrm{~h}$ ) and final cooling $(\approx 5 \mathrm{~h})$. The thermal cycles cause the gradual downward displacement of the wedge at a rate of $\delta_{\mathrm{v}}=0.18 \mathrm{~mm}$ per cycle; the associated rate of permanent horizontal displacement accumulation in the resisting block is $\delta_{\mathrm{h}}=0.02 \mathrm{~mm}$ per cycle (note that, from geometric considerations, $\delta_{\mathrm{h}}=\delta_{\mathrm{v}} \tan \beta$ ).

\section{NUMERICAL MODEL}

A three-dimensional (3D) numerical model was implemented in Abaqus (Abaqus, 2013). In the model, the block, wedge and base are assumed thermo-elastic and are discretised using C3D8 T elements (four nodes, full integration, coupled temperature-displacement elements). Interfaces have an elastic normal response, an elasto-plastic shear response (critical distance to mobilise the interface shear strength $\delta_{\mathrm{j}}^{*}(\mathrm{~m})$ and friction coefficient $\mu$ ) and low thermal conductivity (limited heat transfer across bodies). The properties of materials and interfaces are summarised in Table 1. In the absence of specific interface data, the critical distance to mobilise shear strength is used as a fitting parameter: all experiments are properly predicted with a single value of $\delta_{j}^{*}=1 \times 10^{-4} \mathrm{~m}$.

In all cases, the numerical results closely match the experimental results. For example, Fig. 3 compares numerical and experimental results for the case of a horizontal base $\eta=0^{\circ}$, a wedge-block interface angle of $\beta=6^{\circ}$ and block cyclic temperature amplitude $\Delta T=1 \cdot 4^{\circ} \mathrm{C}$. In agreement with the experimental results, thermal cycles cause the gradual accumulation of downward wedge displacement and associated horizontal block movement. The adopted interface constitutive model causes continuous displacement accumulation rather than the stick-slip response observed in experimental results, which is mainly due to the presence of small asperities in the aluminium frame and the speed at which the wedge accommodates to the temperature change. Modelling of the tangential interface behaviour can be improved by adopting a constitutive model with strain softening or state parameters and a friction law that depend upon the relative displacement rate of the surfaces.

\section{ANALYTICAL SOLUTION}

A closed-form solution is sought to identify the interplay between parameters that govern the macroscale response and to explicitly define the parameter domain for thermomechanical ratcheting. The assumed geometry resembles that shown in Fig. 1, with the following simplifications (a more general case is solved elsewhere (Pasten, 2013)).

- 1D system along the $x$-direction so the wedge-block interface angle is $\beta=0^{\circ}$ (Fig. 1).

- There is no weight transfer from the wedge onto the block 
Table 1. Material properties

\begin{tabular}{l|c|c}
\hline & Acrylic & Aluminium \\
\hline Young's modulus, $E: \mathrm{GPa}$ & $2 \cdot 5$ & 70 \\
Mass density, $\rho: \mathrm{kg} / \mathrm{m}^{3}$ & 1180 & 2700 \\
Interface friction coefficient, $\mu$ & $0 \cdot 42$ & $0 \cdot 5$ \\
Thermal expansion coefficient, $\alpha:$ & 85 & 20 \\
$\quad 10^{-6} /{ }^{\circ} \mathrm{C}$ & & \\
Thermal conductivity, $k_{\mathrm{T}}: \mathrm{W} /(\mathrm{m} \mathrm{K})$ & $0 \cdot 2$ & 210 \\
Specific heat capacity, $c_{\mathrm{p}}: \mathrm{J} /(\mathrm{kg} \mathrm{K})$ & 1500 & 900 \\
Thermal diffusivity, $D_{\mathrm{T}}: \mathrm{m}^{2} / \mathrm{s}$ & $1 \cdot 13 \times 10^{-7}$ & $8 \cdot 64 \times 10^{-5}$ \\
\hline
\end{tabular}

- The resisting block is perfectly rigid and only the wedge experiences thermal expansion.

- The system is wide so that heat diffusion takes place only from boundaries normal to the $x$-direction.

\section{Equilibrium and compatibility}

The maximum shear force per unit out-of plane width $F_{\max }$ $(\mathrm{N} / \mathrm{m})$ that can be mobilised at the base is

$$
F_{\max }=H \gamma L_{\mathrm{B}}(\mu \cos \eta-\sin \eta)-H \gamma L_{\mathrm{W}} \sin \eta
$$

where $\gamma\left(\mathrm{N} / \mathrm{m}^{3}\right)$ is the block unit weight and the other parameters are defined in Fig. 1.

The wedge free thermal expansion $\delta_{\mathrm{T}}(\mathrm{m})$ is constrained by the presence of the block. In fact, the wedge elastic contraction $\delta_{\sigma}(\mathrm{m})$ due to the resisting force $F(\mathrm{~N} / \mathrm{m})$ exerted by the block is

$$
\delta_{\sigma}=\frac{F L_{\mathrm{W}}}{H E}
$$

where $E(\mathrm{~Pa})$ is the material Young's modulus. Then, the displacement the wedge imposes on the rigid block and base joint $\delta_{\mathrm{j}}(\mathrm{m})$ equals

$$
\delta_{\mathrm{j}}=\delta_{\mathrm{T}}-\delta_{\sigma}
$$

Displacements are elastic as long as the joint displacement remains below the elastic threshold $\delta_{\mathrm{j}} \leq \delta_{\mathrm{j}}^{*}$. The interaction force reaches the maximum value $F=F_{\max }$ when $\delta_{\mathrm{j}}=\delta_{\mathrm{j}}^{*}$ and deformations accumulate when $\delta_{\mathrm{j}}>\delta_{\mathrm{j}}^{*}$.

Free thermal expansion $\delta_{T}$ : dependency on exposure time Diffusive heat transport defines the temperature $T(x, t)$ at distance $x$ and time $t$ following changes in boundary temperature (Carslaw \& Jaeger, 1986)

$$
\frac{\partial T(x, t)}{\partial t}=D_{\mathrm{T}} \frac{\partial^{2} T(x, t)}{\partial x^{2}}
$$

The thermal diffusivity $D_{\mathrm{T}}=k_{\mathrm{T}} /\left(\rho c_{\mathrm{p}}\right)\left(\mathrm{m}^{2} / \mathrm{s}\right)$ is proportional to the material thermal conductivity $k_{\mathrm{T}}(\mathrm{W} /(\mathrm{m} \mathrm{K}))$ and inversely proportional to its mass density $\rho\left(\mathrm{kg} / \mathrm{m}^{3}\right)$ and specific heat capacity $c_{\mathrm{p}}(\mathrm{J} /(\mathrm{kg} \mathrm{K}))$. The homogenisation time $t^{*}(\mathrm{~s})$ is the time until the centre of the block experiences $99 \%$ of the imposed boundary thermal change $\Delta T\left({ }^{\circ} \mathrm{C}\right)$. Under diffusion-controlled conditions, the homogenisation time for the wedge can be estimated as (Carslaw \& Jaeger, 1986)

$$
t_{\mathrm{W}}^{*}=0.5 L_{\mathrm{W}}^{2} / D_{\mathrm{T}}
$$

Then, the skin depth $S_{\mathrm{d}}(\mathrm{m})$ affected by a certain exposure time $t_{\exp }(\mathrm{s})$ is

$$
S_{\mathrm{d}}=\left\{\begin{array}{cc}
\left(0 \cdot 5 D_{\mathrm{T}} t_{\exp }\right)^{0.5} & t_{\exp }<t_{\mathrm{W}}^{*} \\
L_{\mathrm{W}} / 2 & t_{\exp } \geq t_{\mathrm{W}}^{*}
\end{array}\right.
$$

Consequently, the wedge free thermal expansion depends on the exposure time relative to the homogenisation time and the imposed temperature change $\Delta T=T_{1}-T_{0}\left({ }^{\circ} \mathrm{C}\right)$

$$
\delta_{\mathrm{T}}=\alpha\left(2 S_{\mathrm{d}}\right) \Delta T
$$

where $\alpha\left(1 /{ }^{\circ} \mathrm{C}\right)$ is the rock thermal expansion coefficient.

\section{Maximum temperature change without plastic displacement}

The maximum temperature change $\Delta T_{\max }$ that the system can sustain without plastic displacement for a given exposure time $t_{\exp }$ can be computed by substituting the free thermal expansion $\delta_{\mathrm{T}}$ calculated for an exposure time $t_{\mathrm{exp}}$ (equation (7)) and the elastic contraction $\delta_{\sigma}$ calculated for $F_{\max }$ (equation (2)) into the compatibility equation at the verge of plastic deformation $\delta_{\mathrm{j}}^{*}=\delta_{\mathrm{T}}-\delta_{\sigma}$ (equation (3)). Solving for $\Delta T_{\max }$ yields

$$
\begin{aligned}
& \Delta T_{\max }=\frac{1}{2 S_{\mathrm{d}} \alpha}\left(\delta_{\mathrm{j}}^{*}+\frac{F_{\max } L_{\mathrm{W}}}{H E}\right) \\
& =\frac{1}{2 S_{\mathrm{d}} \alpha}\left[\delta_{\mathrm{j}}^{*}+\frac{\gamma L_{\mathrm{W}}^{2}}{E}\left(\frac{L_{\mathrm{B}}}{L_{\mathrm{W}}}(\mu \cos \eta-\sin \eta)-\sin \eta\right)\right]
\end{aligned}
$$

The maximum temperature $\Delta T_{\max }$ the system can sustain without plastic displacement decreases when the thermal expansion coefficient $\alpha$, the stiffness $E$ or the slope angle $\eta$ increase. Conversely, $\Delta T_{\max }$ increases when the joint friction coefficient $\mu$ or elastic displacement $\delta_{\mathrm{j}}^{*}$ increases. In dimensionless form, equation (8) can be written as

$$
\begin{aligned}
1= & \frac{\delta_{\mathrm{j}}^{*}}{2 S_{\mathrm{d}} \alpha \Delta T_{\max }}+\frac{L_{\mathrm{W}}}{2 S_{\mathrm{d}}} \frac{\gamma L_{\mathrm{W}}}{E \alpha \Delta T_{\max }} \\
& \times\left(\frac{L_{\mathrm{B}}}{L_{\mathrm{W}}}(\mu \cos \eta-\sin \eta)-\sin \eta\right)
\end{aligned}
$$

\section{DISCUSSION}

\section{Comparison}

Figure 4 shows the variation in $\Delta T_{\max }$ predicted by equation (8) as a function of the relative block-to-wedge length ratio $L_{\mathrm{B}} / L_{\mathrm{W}}$ for the parameters listed in Table 1 and exposure times $t_{\exp }=1 \mathrm{~h}$ (continuous lines) and $t_{\exp }=30 \mathrm{~h}$ (dashed lines). For comparison, the following three plane-strain cases are numerically solved.

- A thermo-elastic wedge and a perfectly rigid block with vertical interface $\beta=0^{\circ}$ (model a, similar to the geometry assumed in the analytical solution).

- A thermo-elastic wedge and a rigid block with inclined interface $\beta=6^{\circ}$ (model b).

- A thermo-elastic wedge and block with vertical interface $\beta=0^{\circ}$ (model c).

In all cases, the wedge-block interface is considered frictionless and thermally isolated. The results in Fig. 4 show the following.

- The analytical model is in close agreement with numerical results (model a) for long exposure times when the full wedge length is involved in thermal dilation. Differences for short exposure times underscore the effects of simplifying assumptions on skin depth $S_{\mathrm{d}}$.

- The close agreement between results obtained with models $\mathrm{a}$ and $\mathrm{b}$, for both short and long exposure times, provides support to the simplifying assumption $\beta=0$ made for the analytical solution.

- Results obtained for model $\mathrm{c}$ as compared to model a show the pronounced effect that the combination of base inclination and thermal expansion in both the wedge and the block has on causing plastic displacements. 


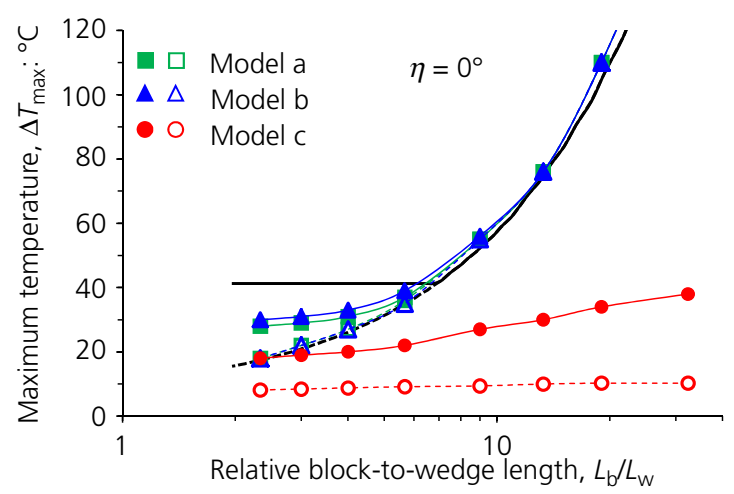

(a)

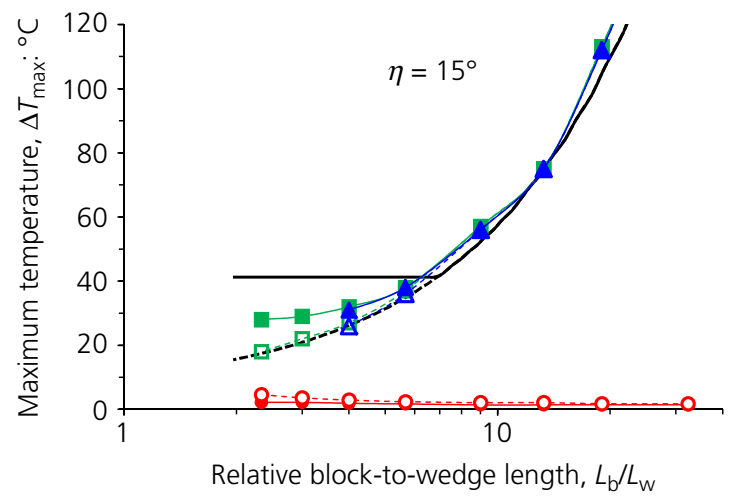

(b)

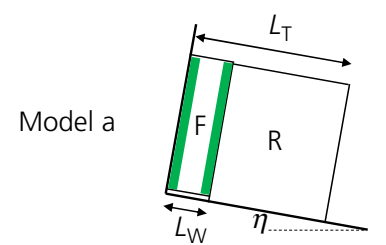

Model b
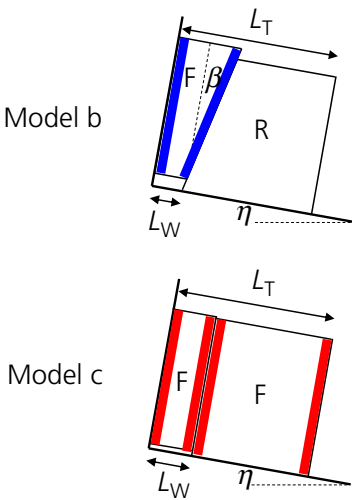

Fig. 4. Maximum temperature change required to cause plastic displacement $\Delta T_{\max }$ as a function of the relative block-to-wedge length $L_{\mathrm{B}} / L_{\mathrm{W}}$. Base inclination $\eta=0^{\circ}$ (a) and $\eta=15^{\circ}$ (b). Continuous and dashed lines correspond to the analytical model (equation (8)) for exposure times $t_{\exp }=1 \mathrm{~h}$ and $t_{\exp }=30 \mathrm{~h}$, respectively. Numerical results for plain-strain models a, $\mathrm{b}$ and $\mathrm{c}$ are shown as symbols. Filled and open symbols correspond to exposure times $t_{\exp }=1 \mathrm{~h}$ and $t_{\exp }=30 \mathrm{~h}$, respectively. $\mathrm{R}$ stands for a rigid element and $\mathrm{F}$ for elastic element. $L_{\mathrm{T}}=L_{\mathrm{B}}+L_{\mathrm{W}}=225 \mathrm{~mm}, H=350 \mathrm{~mm}$ and the material properties are listed in Table 1

- Low critical temperatures $\Delta T_{\max }$ obtained from model c agree with the temperature amplitude that causes plastic displacement in the cyclic stage of the experimental demonstration (Fig. 3(a)).

\section{Alternative failure modes: toppling and sliding}

Models with high slenderness $H / L_{\mathrm{T}}$ are prone to toppling, while low slenderness models favour sliding. The model analysed in Fig. 3 is stable to toppling for any relative blockto-wedge length $L_{\mathrm{B}} / L_{\mathrm{W}}$ and is stable to sliding for $L_{\mathrm{B}} / L_{\mathrm{W}}>$ 4. According to equation (1), the maximum inclination that the model can sustain is $\eta_{\max }=\operatorname{arctangent}\left[\mu L_{\mathrm{B}} /\left(L_{\mathrm{B}}+L_{\mathrm{W}}\right)\right]$.

\section{CONCLUSIONS}

Experimental, numerical and analytical results show that thermo-mechanical coupling can lead to plastic displacement accumulation and ratcheting when a rock mass is subjected to a biased static-force condition, due to a wedgeblock geometry and/or an inclined base plane.

The numerical simulations corroborate the experimental results and agree with the analytical results. In turn, the analytical solutions expose the interplay between the governing parameters, in particular the relative threshold strain in the joint and the thermal strain in the wedge $\left(\delta_{\mathrm{j}}^{*} /\right.$ $\left.2 S_{\mathrm{d}} \alpha \Delta T_{\max }\right)$, the relative elasto-thermal strains $\left(\left(\gamma L_{\mathrm{W}}^{2}\right) /\right.$ $\left(2 S_{\mathrm{d}} E \alpha \Delta T_{\max }\right)$ ) (with the contribution of gravity through the inclination factors) and the relative block-to-wedge size $\left(L_{\mathrm{B}} / L_{\mathrm{W}}\right)$.

Permanent displacements are accentuated by the intensity of the biased force, the amplitude of the thermal cycle and the exposure time, the thermal expansion coefficient of the rock and the joint brittleness (i.e. the threshold deformation for elastic-to-plastic transition).

Thermo-mechanical ratcheting is a gradual failure mechanism that manifests in many exposed rock faces, especially when they are subjected to large-amplitude seasonal temperature changes (see details in Pasten (2013)) and it may also develop in other engineered geosystems. Its parameter domain often plots outside the toppling and sliding domains.

\section{ACKNOWLEDGEMENTS}

Support for this research was provided by the Fulbright USChile Equal Opportunities Scholarship Program, the US National Science Foundation, the Goizueta Foundation and the CONICYT FONDECYT Initiation into research grant 11130363. Antonio Hernandez performed the experimental tests.

\section{REFERENCES}

Abaqus (2013). Abaqus Version 6.13. Providence, RI: Abaqus.

Bakun-Mazor, D, Hatzor, Y. H., Glaser, S. D. \& Carlos Santamarina, J. (2013). Thermally vs. seismically induced block displacements in Masada rock slopes. Int. J. Rock Mech. Mining Sci. 61, 196-211.

Carslaw, H. S. \& Jaeger, J. C. (1986). Conduction of heat in solids. New York, NY: Oxford University Press.

Croll, J. G. (2009). The role of thermal ratcheting in pavement failures. Proc. Inst. Civ. Eng. - Transport 162, No. 3, 127-140.

Gischig, V. S., Moore, J. R., Evans, K. F., Amann, F. \& Loew, S. (2011). Thermomechanical forcing of deep rock slope 
deformation: 1. Conceptual study of a simplified slope. J. Geophys. Res.: Earth Surf. 116, No. 4, F04010.

Greif, V., Simkova, I. \& Vlcko, J. (2014). Physical model of the mechanism for thermal wedging failure in rocks. In Landslide science for a safer geoenvironment (K. Sassa, P. Canuti \& Y. Yin (eds)). Cham (ZG), Switzerland: Springer, pp. 45-50.

Gunzburger, Y., Merrien-Soukatchoff, V. \& Guglielmi, Y. (2005). Influence of daily surface temperature fluctuations on rock slope stability: case study of the Rochers de Valabres slope (France). Int. J. Rock Mech. Mining Sci. 42, No. 3, 331-349.

Hatzor, Y. H. (2003). Keyblock stability in seismically active rock slopes - Snake Path Cliff, Masada. J. Geotech. Geoenviron. 129, No. 8, 697-710.
Pasten, C. (2013). Geomaterials subjected to repetitive loading: implications on energy systems. Atlanta, GA: Georgia Institute of Technology.

Pasten, C. \& Santamarina, J. C. (2014a). Experimental and numerical modeling of thermally-induced ratcheting displacement of geomembranes on slopes. Geosynth. Int. 21, No. 6, 334-341.

Pasten, C. \& Santamarina, J. C. (2014b). Thermally induced long-term displacement of thermoactive piles. J. Geotech. Geoenviron. Engng 140, №. 5, 06014003.

Watson, A. D., Moore, D. P. \& Stewart, T. W. (2004). Temperature influence on rock slope movements at Checkerboard Creek. Proc. 9th Int. Symp. on Landslides, Rio de Janeiro, Brazil, vol. 2, 1293-1298.

\section{WHAT DO YOU THINK?}

To discuss this paper, please email up to 500 words to the editor at journals@ice.org.uk. Your contribution will be forwarded to the author(s) for a reply and, if considered appropriate by the editorial panel, will be published as a discussion. 